\title{
Cadaveric Evaluation of Lumbar Pedicle Morphometry among Nigerians
}

\section{Adeleke Adegboyega Abiodun ${ }^{*}$, Paul Olugbemiga Awoniran ${ }^{2}$, Omobola Aderibigbe Komolafe $^{1}$, Adebowale Oyewumi Tanimowo ${ }^{1}$}

\author{
${ }^{1}$ Department of Anatomy and Cell Biology, Obafemi Awolowo University, Ile-Ife, Nigeria \\ ${ }^{2}$ Department of Human Anatomy, Faculty of Basic Medical Sciences, Redeemer's University, Ede, Osun State, Nigeria \\ Email: *aaabiodun76@yahoo.com
}

How to cite this paper: Abiodun, A.A., Awoniran, P.O., Komolafe, O.A. and Tanimowo, A.O. (2020) Cadaveric Evaluation of Lumbar Pedicle Morphometry among Nigerians. Journal of Biosciences and Medicines, 8, 1-8.

https://doi.org/10.4236/jbm.2020.810001

Received: March 5, 2020

Accepted: September 27, 2020

Published: September 30, 2020

Copyright (c) 2020 by author(s) and Scientific Research Publishing Inc. This work is licensed under the Creative Commons Attribution International License (CC BY 4.0).

http://creativecommons.org/licenses/by/4.0/

\begin{abstract}
Pedicle screw is employed in several cases of spine disorders such as fractures, pseudarthrosis, spondylolisthesis, degenerative changes among others. Its essence is to fix the vertebral body in position until fusion is complete. The success of this technique depends on factors like choice of size of screw for a particular pedicle size and shape. Thus, adequate knowledge of the morphometry of lumbar pedicle may avert intraoperative and postoperative complications associated with this technique, especially, neurological impairments. In this study, we determined the vertical and horizontal diameters, interpedicular distance and gender differences of 180 lumbar vertebral pedicles (140 male, 40 female pedicles) using digital vernier calipers. Results revealed a significant increase in pedicle height and width from L2 to L5. Interpedicular distance increased significantly down the vertebrae from L2 to L5. Mean vertical and horizontal diameters, interpedicular distance were not significantly different in both sexes. This study recommends a thorough check of individual's spinal anatomy in pre-operative assessments.
\end{abstract}

\section{Keywords}

Vertebra, Pedicle Height, Pedicle Width, Interpedicular Distance, Pedicle Screw

\section{Introduction}

Vertebral pedicles are strong cylindrical structures which have a core of cancellous bone surrounded by a strong shell of cortical bone [1] [2]. They have a medial and inferior anatomical relation to the dural sac and exiting nerve roots respectively [3]. 
Inferior or medial penetration of the pedicle cortex during spinal fusion procedures such as pedicle srew fixation (PSF) can result in specific injuries and complications [4].

PSF is a method of spine instrumentation in which a screw of appropriate diameter and length is carefully inserted through the pedicle for spine stabilization [5] [6]. The injuries and complications associated with this procedure include radicular, dura-mater and vascular injuries, leakage of cerebrospinal fluid, pedicle fracture, deep infections, thromboembolism and several other complications linked to important surgeries [7] [8] [9].

The accurate knowledge of pedicle morphometry is of crucial importance as dimensions of pedicle become pivotal information for the selection of screws in related surgeries. Also, knowing its size across populations is crucial to the prevention of peculiar surgery-linked injuries and precise diagnosis in disease conditions related to narrowing and widening of the vertebral canal. This study was conducted to evaluate the morphometry of pedicles of lumbar spines in the Nigerian population so as to document relevant data.

\section{Materials and Methods}

Lumber spines of 18 adult human fresh cadavers (30 - 70 years) were dissected with sex specification of 4 females and 14 males. Cadavers with spine-related gross deformities such as scoliosis, hyperkyphosis or hyperlordosis, were excluded from the study. 180 vertebral pedicles (L1 - L5) were evaluated following dissection, broken vertebrae were also excluded. Sacralization of L5 and lumbarization of S1 was not found in any of the used subjects. All cadavers were Nigerians.

Dissections were performed under macroscopic view in the Gross Anatomy Laboratory of the Department of Anatomy and Cell Biology, Obafemi Awolowo University, Ile-Ife, Nigeria. With the cadavers in ventral decubitus (prone position), incisions were made from T10 to S2 vertebra considering the surface landmarks. Soft tissues were dissected out to allow access to the spine. Muscle dissection was performed as lateral as possible to allow palpation of the transverse processes. The spinous processes, lamina, superior and inferior facets, and transverse processes were removed to expose the pedicles. Measurements were performed with digital Vernier calipers for morphometric evaluation of the lumbar vertebral pedicle. The protocol for this work was approved by Health Research and Ethics Committee, Obafemi Awolowo University, Ile-Ife, Nigeria. Three parameters were measured from L1 to L5 (Figure 1):

- Pedicle Height: it was taken as the maximum right vertical diameter (RVD) on the right pedicle and the maximum left vertical diameter (LVD) of the left pedicle. The point of contact of the main jaws of Vernier caliper was measured in millimeter $(\mathrm{mm})$ on both sides.

- Pedicle Width: it was taken as the maximum right horizontal diameter (RHD) on the right pedicle and maximum left horizontal diameter (LHD) on 
the left pedicle. The point of contact of the main jaws of Vernier caliper was measured in millimeter $(\mathrm{mm})$ on both sides.

- Interpedicular Diameter (IPD): it was determined by measuring the maximum distance between the medial surfaces of the right and left pedicles of the same vertebra. The small jaws of Vernier caliper were positioned to touch the two maximum transverse points of the inner sides of the pedicles. It was measured in millimeter $(\mathrm{mm})$.

\section{Statistical Analysis}

All symmetrical structures were measured bilaterally. SPSS version 22.1 and Microsoft Excel were used for all analyses. Descriptive statistics were presented as means \pm standard deviations (SD).

\section{Result}

Table 1 shows the descriptive analysis of the vertical, horizontal and interpedicular diameters from L1 through L5. In this analysis, all L1 through L5 measurements were taken irrespective of the sex of the cadavers. Hence, it was observed that the height of the pedicle (vertical diameter) increased significantly from L1 to L5 on both sides except on the left side of L2 where an insignificant drop was observed when compared with L1. All lumbar pedicle heights were greater than $15 \mathrm{~mm}$. Height was minimum at L1 on the right but minimum at L2 on the left. The maximum height reading of the pedicle was seen at L5 on both sides. Overall, higher values were recorded on the left than on the right side.

Width of lumbar vertebrae increased significantly from L1 to L5 on both sides. Horizontal diameter was smaller than the vertical diameter from L1-L5. All lumbar pedicle widths were greater than $13 \mathrm{~mm}$. The highest reading was observed on the left side of L5 pedicle while the smallest reading was recorded on the left side of L1. Overall, higher values were recorded on the left side than on the right side.

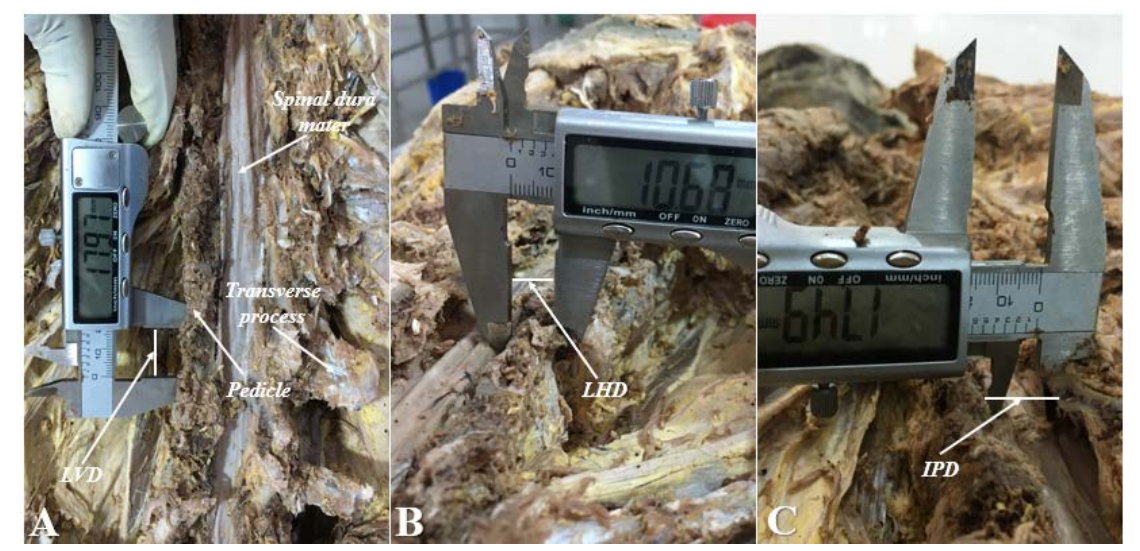

Figure 1. Representative pictures of dissected human cadavers showing (A) left vertical diameter (LVD) on the left pedicle (Pedicle height; L3, superior view); (B) left horizontal diameter (LHD) on the left pedicle (Pedicle width; L3, superior view); (C) Interpedicular distance (IPD) measurement (L3, superior view). 
Table 1. Measurements of pedicle height, width and interpedicular (mean \pm standard deviation).

\begin{tabular}{cccccc}
\hline & \multicolumn{2}{c}{ Vertical Diameter $(\mathrm{mm})$} & \multicolumn{2}{c}{ Horizontal Diameter $(\mathrm{mm})$} & $\begin{array}{c}\text { Interpedicular } \\
\text { Diameter }(\mathrm{mm})\end{array}$ \\
\hline & Left & Right & Left & Right & \\
\hline & $\mathrm{p}<0.0001^{\mathrm{a}}$ & $\mathrm{p}<0.0001^{\mathrm{b}}$ & $\mathrm{p}=\mathbf{0 . 0 0 2}^{\mathrm{c}}$ & $\mathrm{p}=\mathbf{0 . 0 0 2}^{\mathrm{d}}$ & $\mathrm{p}<0.0001^{\mathrm{e}}$ \\
\hline L1 & $15.87 \pm 1.74$ & $15.86 \pm 1.74$ & $13.12 \pm 2.21$ & $13.24 \pm 2.28$ & $17.64 \pm 1.60$ \\
L2 & $15.76 \pm 1.75$ & $15.87 \pm 1.94$ & $13.99 \pm 2.31$ & $13.83 \pm 2.39$ & $17.27 \pm 2.90$ \\
L3 & $16.59 \pm 1.72$ & $16.53 \pm 1.57$ & $15.19 \pm 2.35$ & $14.97 \pm 2.42$ & $18.79 \pm 2.50$ \\
L4 & $17.86 \pm 1.49$ & $17.86 \pm 1.61$ & $15.94 \pm 2.74$ & $16.04 \pm 2.57$ & $20.49 \pm 3.27$ \\
L5 & $19.09 \pm 2.98$ & $18.92 \pm 3.11$ & $16.53 \pm 2.72$ & $16.51 \pm 2.68$ & $21.73 \pm 3.52$ \\
\hline
\end{tabular}

${ }^{a}$ The distribution of left vertical diameter was significantly different across categories of lumbar vertebrae bones (L1 to L5), hence, $\mathrm{p}<0.0001$. ${ }^{\mathrm{b}}$ The distribution of right vertical diameter was significantly different across categories of lumbar vertebrae bones ( $\mathrm{L} 1$ to $\mathrm{L} 5$ ), hence, $\mathrm{p}<0.0001$. ${ }^{\text {Th }}$ The distribution of left horizontal diameter was significantly different across categories of lumbar vertebrae bones (L1 to L5), hence, $p=$ 0.002 . ${ }^{\mathrm{d}}$ The distribution of right horizontal diameter was significantly different across categories of lumbar vertebrae bones ( $\mathrm{L} 1$ to $\mathrm{L} 5$ ), hence, $\mathrm{p}=0.002$. ${ }^{\mathrm{e}}$ The distribution of interpedicular diameter was significantly different across categories of lumbar vertebrae bones (L1 to L5), hence, $\mathrm{p}<0.0001{ }^{*} \mathrm{p}$-value is only significant when $\mathrm{p}<0.05$. ${ }^{*}$ significant difference was performed using non-parametric analysis method with Kruskal Wallis Test. This is because the test samples are less than 50, being 4 females and 14 males, total of 18.

Mean interpedicular distances increased significantly from L2 to L5 (Table 1). The maximum interpedicular distance was seen at L5 whereas the minimum was observed at L2.

Table 2 shows the gender difference in the vertical, horizontal and interpedicular diameter from L1 through L5. Result showed an insignificant difference in the average hight of L1, L2 and L5 lumbar pedicles. Meanwhile, the left and right vertical diameters, left and right horizontal diameters and the interpedicular distance were not significantly different between the categories of sex.

The mean interpedicular distances in male was wider at the level of L1 - L4 than in female. There was a change at the level of L5 where values were higher in female than in male. Although, the maximum difference did not exceed two millimeters $(2 \mathrm{~mm})$ at any vertebral level (Figure 2).

\section{Discussion}

Morphometric data of vertebral pedicles is of importance in preoperative planning and also in designing pedicle screws and other implantable devices [10]. A wrongly positioned pedicle screw may cause major injury to vital structure such as bundle of nerves that send signals to other parts of the body, pedicle cortex and nerve roots [11]. Once pedicle size is known, it would be possible to evaluate if the pedicle screws would have diameters that could be considered as safe [12]. Thus, for safer pedicle screw placement it is imperative to understand the dimensions of pedicles, possible variations and angulations for the development of techniques and devices for spinal instrumentation. 
Table 2. Measurements of gender difference of pedicle height, width and interpedicular (mean \pm standard deviation).

\begin{tabular}{|c|c|c|c|c|c|}
\hline & \multicolumn{2}{|c|}{ Vertical Diameter (mm) } & \multicolumn{2}{|c|}{ Horizontal Diameter (mm) } & \multirow{2}{*}{$\begin{array}{l}\text { Interpedicular } \\
\text { Diameter }(\mathrm{mm})\end{array}$} \\
\hline & Left & Right & Left & Right & \\
\hline L1: Male & $16.14 \pm 1.87$ & $16.11 \pm 1.88$ & $13.36 \pm 2.45$ & $13.51 \pm 2.51$ & $17.82 \pm 1.62$ \\
\hline Female & $14.93 \pm 0.62$ & $14.99 \pm 0.79$ & $12.31 \pm 0.85$ & $12.33 \pm 0.82$ & $17.01 \pm 1.54$ \\
\hline p-value ${ }^{a}$ & 0.277 & 0.192 & 0.442 & 0.382 & 0.327 \\
\hline L2: Male & $15.72 \pm 1.96$ & $15.61 \pm 2.00$ & $14.35 \pm 2.51$ & $14.14 \pm 2.62$ & $17.41 \pm 2.88$ \\
\hline Female & $16.05 \pm 0.84$ & $16.77 \pm 1.60$ & $12.75 \pm 0.71$ & $12.76 \pm 0.78$ & $16.80 \pm 3.38$ \\
\hline$p$-value ${ }^{b}$ & 0.798 & 0.645 & 0.192 & 0.442 & 0.645 \\
\hline L3: Male & $16.52 \pm 1.95$ & $16.46 \pm 1.78$ & $15.68 \pm 2.44$ & $15.41 \pm 2.57$ & $18.81 \pm 2.59$ \\
\hline Female & $16.82 \pm 0.43$ & $16.79 \pm 0.44$ & $13.46 \pm 0.62$ & $13.41 \pm 0.66$ & $18.70 \pm 2.48$ \\
\hline p-value ${ }^{c}$ & 1.00 & 1.00 & 0.101 & 0.192 & 0.721 \\
\hline L4: Male & $17.87 \pm 1.69$ & $17.88 \pm 1.83$ & $16.41 \pm 2.92$ & $16.56 \pm 2.68$ & $20.59 \pm 3.45$ \\
\hline Female & $17.85 \pm 0.40$ & $17.79 \pm 0.41$ & $14.27 \pm 0.76$ & $14.23 \pm 0.76$ & $20.11 \pm 2.94$ \\
\hline$p$-value $e^{d}$ & 1.00 & 0.959 & 0.277 & 0.277 & 0.574 \\
\hline L5: Male & $18.95 \pm 3.36$ & $18.77 \pm 3.53$ & $17.19 \pm 2.77$ & $17.16 \pm 2.74$ & $21.62 \pm 3.87$ \\
\hline Female & $20.16 \pm 1.41$ & $20.03 \pm 1.44$ & $14.69 \pm 1.57$ & $14.70 \pm 1.55$ & $22.03 \pm 2.63$ \\
\hline p-value $e^{e}$ & 0.559 & 0.687 & 0.107 & 0.107 & 0.687 \\
\hline
\end{tabular}

${ }^{*} \mathrm{p}$-value is only significant when $\mathrm{p}<0.05 .{ }^{*}$ significant difference was performed using non-parametric analysis method with Kruskal Wallis Test.

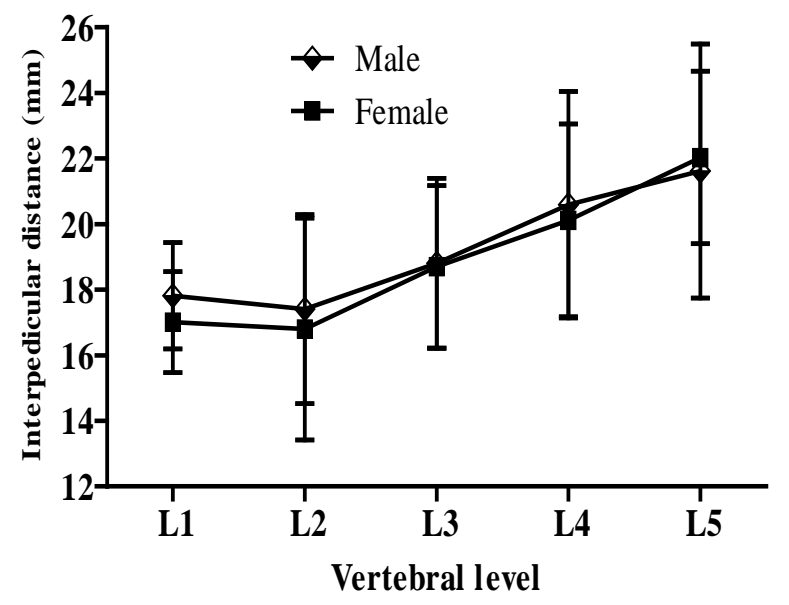

Figure 2. Mean gender difference in interpedicular distance.

Result from this study revealed a progressive increase in right and left vertical diameter from L2 to L5 as shown in Table 1 and Table 2. These imply that the more distal lumbar vertebral pedicles could safely receive larger diameter pedicular screws. Matuoka and Júnior [3] reported that the lumbar pedicular screws in circulation have a diameter ranging from $5.0 \mathrm{~mm}$ to $7.5 \mathrm{~mm}$. Therefore, we agree that the lumbar vertebral pedicle in circulation can be safely introduced in surgical procedures as the minimum average diameter recorded in this study was 10.36 at the level of L2 vertebra. The trend of vertical pedicular diameter observed in this study is consistent with the previous reports of Tan et al. [13] and 
Karkhyle et al. [10] of Chinese Singaporeans and Maharahtarian populations respectively. However, it's against the report of Singel et al. [5] who recorded a decrease in vertical height in lower lumbar pedicles in Saurashtra region of India. The reason for this contrast can be due to racial variation.

Result from this study revealed that the horizontal diameter of the lumbar vertebral pedicles on either side progressively increased down the vertebrae in both sexes (Table 1), being largest at L5 pedicle followed by L4, L3 then L2 and smallest at L1. The difference between the L1 and L2 was statistically significant ( $p=0.0067)$, the same was true for L2 and L3 ( $p=0.0017)$, L3 and L4 ( $p<$ $0.0001), \mathrm{L} 4$ and L5 ( $\mathrm{p}=0.0238)$ using paired " $\mathrm{t}$ " test. Literature reveals that lumbar pedicle screws in circulation have their diameters ranging from $5.0 \mathrm{~mm}$ to $7.5 \mathrm{~mm} \mathrm{[3].} \mathrm{Since} \mathrm{the} \mathrm{minimum} \mathrm{diameter} \mathrm{in} \mathrm{the} \mathrm{present} \mathrm{study} \mathrm{is} 9.24$ on the left side at L2 vertebral level, lumbar pedicles could receive the pedicle screws in circulation. Although, care must be taken in the processes of surgical fixation as this value is close to the marketed pedicular screw diameter considering that soft tissues like dura sac and nerve roots are lying medial to this structure. One of the literatures reviewed reported that below L1, the medial side of the pedicle is almost touching the cauda equine [3]. This is in agreement with Amonoo-Kuofi et al. [8]; Singel et al. [5] and Ebraheim et al. [14]. They also reported similar increase in horizontal diameter down the vertebrae.

Data form this study revealed a proportionate increase in the width of the vertebral canal with the level of vertebra except at L2 where a narrowing was observed. Juxtaposition of individual foramen constitute a long tubular vertebral canal that houses the spinal cord to the level of the first or second lumbar vertebra [15]. Below this level, the vertebral canal is occupied by spinal nerve roots and meninges. Specifically, a fibrous strand, filum terminale continues from the spinal cord down to the coccyx. Impingement of these structures may result into serious clinical problems [16]. Surgeons should consider a possible disproportionate diameter in interpedicular distance as observed at the level of L2 in this study in preoperative planning to prevent the impingement of neural structures.

\section{Conclusion}

Data from this study although agree with the safe use of the pedicle screws in circulation, worthy of note is its revelation of possible variations in the dimensions of pedicle height and interpedicular distance. These must be considered in preoperative planning and screw designing in order to facilitate a restricted intraosseous trajectory considering the relation of soft tissues and nerve roots to these structures knowing that an impingement could result in serious clinical problems. This study recommends a thorough check of individual's spinal anatomy in pre-operative assessments.

\section{Funding}

This research did not receive any specific grant from funding agencies in the 
public, commercial, or not-for-profit sectors.

\section{Conflicts of Interest}

No competing interests declared.

\section{References}

[1] Clements, D.H., Morledge, D.E. and Martin, W.H. (1996) Evoked and Spontaneous Electromyography to Evaluate Lumbosacral Pedicle Screw Placement. Spine, 21, 600-604. https://doi.org/10.1097/00007632-199603010-00013

[2] Defino, H.L.A. and Vendrame, J.R.B. (2001) Role of Cortical and Cancellous Bone of the Vertebral Pedicle in Implant Fixation. European Spine Journal, 10, 325-333. https://doi.org/10.1007/s005860000232

[3] Matuoka, C.M. and Júnior, R.B. (2002) Anatomical Study of Lumbar Vertebral Pedicle and Adjacent Neural Structures. Acta Ortopedica Brasileira, 10, 25-34. https://doi.org/10.1590/S1413-78522002000300004

[4] Stein, A.A., Vrionis, F., Espinosa, P.S., et al. (2018) Report of an Isolated L5 Radiculopathy Caused by an L2-3 Disc Herniation and Review of the Literature. Cureus, 10, e2552. https://doi.org/10.7759/cureus.2552

[5] Singel, T.C., Patel, M.M. and Gohil, D.V. (2004) A Study of Width and Height of Lumbar Pedicles in Saurashtra Region. Journal of the Anatomical Society of India, 53, 4-9.

[6] Tyagi, S., Chhabra, S. and Narayan, R.K. (2017) Morphometric Study of Width and Height of Lumbar Pedicles in Population of Haryana. International Journal of Applied Dental Sciences, 3, 78-81.

[7] Lonstein, J.E., Denis, F., Perra, J.E., Pinto, M.R., Smith, M.D. and Winter, R.B. (1999) Complications Associated with Pedicle Screw. Journal of Bone and Joint Surgery, 11, 1519-1528. https://doi.org/10.2106/00004623-199911000-00003

[8] Amonoo-Kuofi, H.S. (1995) Age Related Variations in the Horizontal and Vertical Diameters of the Pedicles of Lumbar Spine. Journal of Anatomy, 186, 321-328.

[9] Vanichchorn, J.S., Vaccaro, A.R., Cohen, M.J. and Cotler, J.M. (1997) Potential Large Vessel Injury during Thoracolumbar Pedicle Screw Removal. Spine, 22, 110-113. https://doi.org/10.1097/00007632-199701010-00018

[10] Karkhyle, L. and Siraz, M.A. (2015) Morphometric Study of the Lumbar Vertebral Pedicle in Maharahtarian Population. Journal of Evolution of Medical and Dental Sciences, 4, 5277-5285. https://doi.org/10.14260/jemds/2015/773

[11] Weinstein, J.N., Sprat, K.F., Spengler, D., Brick, C. and Reid, S. (1988) Spinal Pedicle Fixation: Reliability and Validity of Roentgenogram-Based Assessment and Surgical Factors on Successful Screw Placement. Spine, 13, 1012-1018. https://doi.org/10.1097/00007632-198809000-00008

[12] Chaynes, P., Sol, J.C., Vaysse, P.H., Bécue, J. and Lagarrigue, J. (2000) Vertebral Pedicle Anatomy in Relation to Pedicle Screw Fixation: A Cadaver Study. Surgical and Radiologic Anatomy, 23, 85-90. https://doi.org/10.1007/s00276-001-0085-Z

[13] Tan, S.H., Teo, E.C. and Chua, H.C. (2004) Quantitative Three-Dimensional Anatomy of Cervical, Thoracic and Lumbar Vertebrae of Chinese Singaporeans. European Spine Journal, 13, 137-146. https://doi.org/10.1007/s00586-003-0586-Z

[14] Ebraheim, N.A., Xu, R., Darwich, M. and Yeasting, R.A. (1997) Anatomic Relations between the Lumbar Pedicle and the Adjacent Neural Structure. Spine, 22, 2338-2341. 
https://doi.org/10.1097/00007632-199710150-00003

[15] Agur, A.M.R. and Dalley, A.F. (2013) Grant Atlas of Anatomy. Thirteenth Edition, Lippincott Williams \& Wilkins, Philadelphia.

[16] Standering, S., Borley, N.R., Collins, P., Crossman, A.R., Gatzoulis, M.A., Healy, J.C., Johnson, D., Mahadevan, V., Newell, R.I.M. and Wigley, C.B. (2008) Gray's Anatomy: The Anatomical Basis for Clinical Practice. 40th Edition, Churchill Livingstone, London, 1185-1190. 